\title{
A STUDY ON MIGRATORY POPULATION IN INDIA: SOME SELECTED STATES
}

\author{
Dr. Anjan Chakravarty ${ }^{*}{ }^{\circledR}$ \\ ${ }^{* 1}$ Management Consultant, Assistant Professor (Management), Department of Commerce \& \\ Business Administration (Morning), St. Xavier's College, Kolkata Guest Faculty, Department of \\ Business Management, University of Calcutta, India
}

DOI: https://doi.org/10.29121/granthaalayah.v8.i6.2020.444

Article Type: Case Study

Article Citation: Dr. Anjan Chakravarty. (2020). A STUDY ON MIGRATORY POPULATION IN INDIA: SOME SELECTED STATES. International Journal of Research GRANTHAALAYAH, 8(6), 163-168. https://doi.org/10.29121/granthaa layah.v8.i6.2020.444

Received Date: 10 May 2020

Accepted Date: 29 June 2020

Keywords:

Study on Migratory

Population in India

States

\begin{abstract}
India is the motherland of diverse culture, beliefs and traditions. Indians have lived through ages with the maxim "Unity in Diversity". In this so varied nature of population, migrations intra-state and inter-state, as well as, international from bordering countries have affected the characteristics of the inhabitants. In this study, we are aiming to assess the nature of population India has, both in rural and urban categories and how these two categories of population are correlated with each other and try to analyze factors which create an impact on the character of the population. We have selected four states, namely, Gujarat, Maharashtra, Bihar and West Bengal for the purpose of our learning.
\end{abstract}

\section{INTRODUCTION}

\subsection{PRELUDE}

The population of India as per 2011 census has touched the mark of 121 crore. India added 181.5 million to its population since 2001, slightly lower than the population of Brazil. India, with $2.4 \%$ of the world's surface area, accounts for $17.5 \%$ of its population. Of the 121 crore Indians, 83.3 crore $(68.84 \%)$ live in rural areas while 37.7 crore stay in urban areas. 45.36 crore people in India are migrants, which is $37.8 \%$ of total population.

The population of India census wise is as follows:

\begin{tabular}{|c|c|}
\hline Census & Population of ('000) \\
\hline 1951 & 361088 \\
\hline 1961 & 439235 \\
\hline 1971 & 548160 \\
\hline 1981 & 683329 \\
\hline 1991 & 846421 \\
\hline 2001 & 1028737 \\
\hline 2011 & 1210855 \\
\hline
\end{tabular}

(c) 2020 The Author(s). This is an open access article distributed under the terms of the Creative Commons Attribution License, which permits unrestricted use, distribution, and reproduction in any medium, provided the original author and source are credited. 
India is the homeland of major belief systems such as Hinduism, Buddhism, Sikhism and Jainism, while also being home to several indigenous faiths and tribal religions which have survived the influence of major religions for centuries.

Ever since its inception, the Census of India has been collecting and publishing information about the religious affiliations as expressed by the people of India. In fact, population census has the rare distinction of being the only instrument that collects this diverse and important characteristic of the Indian population.

In this study, we are aiming to assess the nature of population India has, both in rural and urban categories and how these two categories of population are correlated with each other and try to analyze factors which create an impact on the character of the population

We are considering the population of the following states for our study, namely, Gujarat, Maharashtra, Bihar and West Bengal. These states have been randomly selected two from Western part of the country and two from the eastern part. Gujarat and Maharashtra are coined as industrially developed states, where as West Bengal, which was once the most industrial developed state in the fifties and sixties has lost much of its glory and Bihar which is considered as a backward state

\begin{tabular}{|c|c|c|c|c|c|c|c|c|}
\hline \multicolumn{9}{c|}{ Population } \\
\hline Census & Rural & Urban & Rural & Urban & Rural & Urban & Rural & Urban \\
\hline Year & Bihar & Bihar & West Bengal & West Bengal & Gujarat & Gujarat & Maharashtra & Maharashtra \\
\hline 1951 & 27219 & 1866 & 20018 & 6282 & 11835 & 4428 & 22802 & 9201 \\
\hline 1961 & 32261 & 2581 & 26385 & 8541 & 15317 & 5317 & 28391 & 11163 \\
\hline 1971 & 38770 & 3356 & 33345 & 10967 & 19201 & 7497 & 34701 & 15711 \\
\hline 1981 & 47158 & 5145 & 40134 & 14447 & 23484 & 10602 & 40789 & 21994 \\
\hline 1991 & 57819 & 6712 & 49370 & 18708 & 27064 & 14246 & 48396 & 30542 \\
\hline 2001 & 74317 & 8682 & 57749 & 22427 & 31741 & 18930 & 55778 & 41101 \\
\hline 2011 & 92341 & 11758 & 62183 & 29093 & 34695 & 25745 & 61556 & 50818 \\
\hline
\end{tabular}

The rural population has been considered as an independent variable and the urban population as the dependent variable. This is considered with relevance to the fact that the urban population is much more mobile in comparison to the rural population in India.

Let us consider the states individually:

\section{Bihar}

A correlation between the urban and the rural population yields the following results:

\begin{tabular}{|c|c|c|c|}
\hline Correlation & Coefficient of Determination & Adjusted R2 & Sig \\
\hline 0.998 & 0.996 & 0.996 & 0.000 \\
\hline
\end{tabular}

\begin{tabular}{|c|c|c|c|}
\hline Segment & Mean & Standard Deviation & Coefficient of Variation \\
\hline Rural Bihar & 52840 & 23652 & $45 \%$ \\
\hline Urban Bihar & 5728 & 3578 & $62 \%$ \\
\hline
\end{tabular}

\section{West Bengal}

Similarly, a correlation between the urban and the rural population yields the following results:

\begin{tabular}{|c|c|c|c|}
\hline Correlation & Coefficient of Determination & Adjusted R & Sig \\
\hline 0.982 & 0.963 & 0.956 & 0.000 \\
\hline
\end{tabular}

\begin{tabular}{|c|c|c|c|}
\hline Segment & Mean & Standard Deviation & Coefficient of Variation \\
\hline Rural West Bengal & 41312 & 15873 & $38 \%$ \\
\hline Urban West Bengal & 15780 & 8169 & $51 \%$ \\
\hline
\end{tabular}




\section{Gujarat}

Likewise, a correlation between the urban and the rural population yields the following results:

\begin{tabular}{|c|c|c|c|}
\hline Correlation & Coefficient of Determination & Adjusted R & Sig \\
\hline 0.967 & 0.935 & 0.922 & 0.000 \\
\hline
\end{tabular}

\begin{tabular}{|c|c|c|c|}
\hline Segment & Mean & Standard Deviation & Coefficient of Variation \\
\hline Rural Gujarat & 23333 & 8438 & $36 \%$ \\
\hline Urban Gujarat & 12395 & 7800 & $62 \%$ \\
\hline
\end{tabular}

\section{Maharashtra}

Correspondingly, a correlation between the urban and the rural population yields the following results:

\begin{tabular}{|c|c|c|c|c|}
\hline \multirow{2}{*}{\begin{tabular}{|c|} 
Correlation \\
0.984 \\
\end{tabular}} & \multicolumn{2}{|c|}{ Coefficient of Determination } & Adjusted $\mathrm{R}^{2}$ & Sig \\
\hline & & 0.968 & 0.961 & 0.000 \\
\hline Segment & Mean & Standard Deviatio & Coefficien & of Variation \\
\hline Rural Maharashtra & 41773 & 14267 & & $4 \%$ \\
\hline Urban Maharashtra & 25790 & 15750 & & $1 \%$ \\
\hline
\end{tabular}

\section{INFERENCES}

- Considering all the states there is a very high correlation between the rural and urban population. The change in the rural population will highly affect the change in the urban population. The degree of variations of the rural and urban population are very significant since it exhibits a highly dependable data which has a very high correlation amongst themselves.

The coefficient of Determination values here clearly shows that there is a good fit of the regression line with the data. Moreover, the Adjusted $\mathrm{R}^{2}$ further reinforces the fact that the model has a high level of significance lso, $\mathrm{p}$ (sig) $<0.05$, which evidently indicates that the models are statistically valid.

With respect to the strength in correlation between the rural and the urban population Bihar has the strongest correlation followed by Maharashtra, succeeded by West Bengal and Gujarat. This is attributed to the fact that there is a movement of people from the rural to the urban areas, since each segment population has a strong correlation with the other. People are moving to the urban bases in search of jobs.

- In Bihar both the rural and urban bases are weak. However, the rural base is weaker and people are moving to the urban sector in search of employment which would yield them a better living. Migration in Bihar is common, both within the state and from the state to other parts of the country. The vast majority of migration in Bihar is cyclical labour migration by vulnerable groups. Migrants from Bihar are taking up less agricultural work than in the past, and are increasingly moving to work in construction instead. Agriculture remains the primary source of employment within the villages but Bihar is known to suffer from the vagaries of the weather. Droughts and floods are recurrent and can have devastating effects on people, livestock and the village economy. The relatively stagnant Bihar agriculture has not been able to provide enough employment for a growing population. The search for employment opportunities outside agriculture has been rising, be it through migration or commuting from the village. The incidence of migration varies widely across villages. The proportion of "migrant households" (households that had had at least one member working outside the village in the course of the year) ranges from $26 \%$ and $86 \%$. This high correlation of 0.998 further justifies the phenomenon discussed.

- In Maharashtra the rapid industrialization has led to the movement of rural population to the cities like Mumbai, Pune etc. in search of better livelihood in the areas of Information Technology, grape processing, gems and jewellery, textiles, leather, food processing floriculture etc. Therefore, this has led to the movement of population from the rural to the urban bases more positively. Only 25.7 per cent persons from rural areas were reported to be employed before migration which substantially increased to 87.4 per cent after migration. It may be noted that the rural female employment increased the most on migration as compared 
to their counterpart in urban area and also to the male population in both the areas. There is a significant increase in the labour force from 26.5 percent to 88.4 percent in rural and from 32.1 per cent to 71.4 per cent in urban area. The information clearly indicates that migration enables people to find employment. This is attributed to the the fact that there exists a considerable correlation (0.984) amongst the rural and urban population.

- In Gujarat, the state government has introduced schemes like the Garib Kalyan Mela, Krishi Mohatsav and Jyotigram Yojana have been instrumental in the overall development of the rural areas. The Garib Kalyan Mela, a ground-breaking program of the Government of Gujarat makes it easier for the people to receive entitlements from the government.. The Government has organized around 1000 Garib Kalyan Melas resulting in 85 lakh people receiving benefits worth 12,500 crores from the state government. These schemes have resulted in a substantial improvement in the quality of life in villages. The overall industrial development of the state has led to increased employment opportunities in villages. Owing to these factors, migration from rural to urban areas has reduced by 33 percent, justifying a comparatively lower correlation of 0.967 .

- In West Bengal opportunities in urban areas for employment, education etc has been a pull factor attracting migration from rural to urban areas and from smaller towns and cities to larger urban areas. There is also some migration in the opposite direction due to various reasons. However, several measures undertaken by the state government to boost up the rural economy has also harnessed the migration of the population from the rural to the urban areas. It has fostered a movement of population from the urban to the rural sector. Setting up of a fund of Rs 100 crore to help distressed sale-affected farmers, stipend under the state's Kanyashree scheme to a girl child, Rupashree scheme to help to help poor parents in the marriage of their daughter, 100 days of work in a year, rural infrastructural developments have helped to reduce the rural migration to the urban areas. This state has a peculiar characteristic having a rural population of high hopes and aspirations to support and enjoy the benefits of an urban life together with an attraction of the benefits advanced to the rural mass for their social well being.

- The Coefficient of Variation (CV) of the different states clearly indicate that the characteristics of the population has been greatly affected by the migration of population within the state and outside. Search of new and/or better employment has been one of the most important reasons for migration of workers in Bihar. In fact more than two third of the migrations furnish 'search for employment' and 'better wage' as the primary reason for their migration. This is also found true in the case of migrating population in West Bengal. In addition to these, education, business, marriage and natural calamities, have been the important reasons as well.

- In West Bengal there has also been influx of population, as well, not only from other Indian states but also from the neighbouring country Bangladesh. Economic push factors that motivated people to leave Bangladesh have been 1) Instability and economic depression in Bangladesh, 2) Poverty, 3) Lack of employment opportunity, 4) Struggle for livelihood, 5) Forced grabbing of landed property from minority group in Bangladesh, 6) Economic insecurity 7) Lack of industrialization. This phenomenon has been persistent since the creation of Bangladesh in 1971.

Maharashtra is the top destination for migrants from other states with a population of 43 thousand migrants who had migrated under 1 year, according to census 2001 data. The could be attributed to the economic growth through industrialization that has taken place in Maharashtra over the years. However intra state migration in Maharashtra has been reasoned as follows: In search of employment, Business, Transfer of service/ contract, Proximity to place of work, Education, Social/ political problems, Displacement by development project, Housing Problems heath care etc.

Gujarat is emerging as a prominent destination state for in-migrants which can be attributed to its rapid economic growth. Improvement in its industrial sector performance has led to recent inflow of formal sector workers from other states, primarily from Maharashtra. This shows that economic factors are a major factor of migration. It could be postulated that going ahead, Gujarat could become the top destination state for inmigrants in search of better economic opportunities and it wouldn't be a surprise to notice Maharashtra as the major state of origin of such migrant flows. The principal reason for migration within the state and without has been business. With Surat coming up as a major diamond industry hub, there there has been 
migration to Surat not only from Saurashtra but other states like West Bengal, Orissa and Rajasthan. People have also moved to Jamnagar because of industrialization.

- The social, cultural and economic characteristics of the population have largely been affected because of the migrations of the population, intrastate as well as interstate or from the influx of the population from the bordering country. The population has become very cosmopolitan. This is more evident in the urban mass than that of the rural. The Coefficient of Variations of the urban population greater than that of the rural population, in each state under study justifies the fact that there are large variations in the characteristics and more so in the urban than rural areas.

\section{RECOMMENDATIONS}

- Rapid urbanization through migration has brought in development in the country which cannot be ignored. The four key areas in which urbanization has brought in development are as follows : i) Labour Demand and Supply - fills gaps in demand for and supply of labour; efficiently allocates skilled and unskilled labour; cheap labour, disciplined and willingness to work ii) Remittances - provides insurance against risks to households in the areas of origin; increases consumer expenditure and investment in health, education and assets formation iii) Return Migration - brings knowledge, skills and innovation (these are known as social remittances) iv) Skill Development - migration is an informal process of skill development. It enhances knowledge and skills of migrants through exposure and interaction with the outside world. New skills are learnt from co-workers and friends at the place of destination. Therefore migration with the nation and international should be encouraged by the Government.

- However, migration should be balanced and for this reason Government should look roads for investments both in the rural and urban sectors. Industrialization is a must for such balancing effects in the population amongst the states.

- Employment opportunities should be created more in the villages so that the influx and efflux of the population to and from the rural could be poised. Infrastructural amenities should also be created to make rural sector more attractive to the population. Stores in countryside should have all the essential provisions required by the consumers for their daily needs. Rural Marketing by the companies should be made more meaningful. Similar balance should be created in case of international migrations. This stability could be an imperative factor to place India amongst the developed nations of the world. The synchronization between the migrations of rural and urban population would an essential aspect to position India amongst the advanced nations of the world.

\section{SOURCES OF FUNDING}

None.

\section{CONFLICT OF INTEREST}

None.

\section{ACKNOWLEDGMENT}

None.

\section{REFERENCES}

[1] Reserve Bank of India: HANDBOOK OF STATISTICS ON INDIAN STATES, May 5, 2018.

[2] "The Gujarat "January 2012 issue Cover Story - The Panchayat Power.

[3] Indrajit Roy: International Growth Centre: Enhancing Mobility: Political and Social Rights for Circular labour migrants (Policy Brief). 
[4] Directorate of Economics and Statistics, Planning Development, Government of Maharashtra: A Report on Migration Particulars based on data collected in State sample of 64th Round of NSS (July 2007 - June 2008)

[5] Indranil Roy Chowdhury: Financial Express February 1, 2018: Bengal Budget focuses on Rural Sector.

[6] Anup K. Karan: Changing Pattern of Migration from Rural Bihar.

[7] Pranati Datta: Population Studies Unit, Indian Statistical Institute: Immigration from Bangladesh to West Bengal.

[8] Aritra Chakraborty: January 20, 2014: Strength and Harmonize Resaerch and Action: Recent Trends in migration flows across states.

[9] Himanshu Kaushik, TNN: December 5,2016: Gujarat Leading State in Business Migration

[10] Ram B. Bhagat: International Institute for Population Sciences: Migration and Urban Transition in India. 